\title{
Development and Characterization of Carob Flour Based Functional Spread for Increasing Use as Nutritious Snack for Children
}

\author{
Sema Aydın ${ }^{1}$ and Yüiksel Özdemir ${ }^{2}$ \\ ${ }^{1}$ Department of Food Engineering, University of Mersin, Ciftlikkoy, 33343 Mersin, Turkey \\ ${ }^{2}$ Department of Gastronomy and Culinary Arts, Toros University, Yenişehir, 33140 Mersin, Turkey \\ Correspondence should be addressed to Sema Aydın; sema_aydin95@hotmail.com
}

Received 3 July 2016; Revised 5 October 2016; Accepted 30 October 2016; Published 12 January 2017

Academic Editor: Angel A. Carbonell-barrachina

Copyright (c) 2017 S. Aydın and Y. Özdemir. This is an open access article distributed under the Creative Commons Attribution License, which permits unrestricted use, distribution, and reproduction in any medium, provided the original work is properly cited.

\begin{abstract}
Carob flour enriched functional spread was developed and textural, sensory, colour, and some nutritional properties of the product were investigated. Spread samples were prepared with major ingredients for optimisation and minor ingredients for improving texture and aroma. Major ingredients were carob flour and hydrogenated palm oil (HPO) and minor ingredients were commercial skim milk powder, soya flour, lecithin, and hazelnut puree. The ratio of major ingredients was optimised using sensory scores and instrumental texture values to produce a carob spread that most closely resembles commercial chocolate spread (control), in both spreadability and overall acceptability. The amounts of minor ingredients (milk powder, 10\%; soybean flour, 5\%; lecithin, $1 \%$; hazelnut puree, $4 \%$ ) were kept in constant ratio (20\%). Addition of hydrogenated palm oil (HPO) decreased the hardness and hardness work done (HWD) values in contrast to carob flour. Higher rates of carob flour were linked to lower lightness, greenness, and yellowness values. Spread was optimised at $38 \mathrm{~g}$ carob flour $/ 100 \mathrm{~g}$ spread and $42 \mathrm{~g}$ hydrogenated palm oil/100 g spread level and the formulation tended to receive the highest sensory scores compared to other spreads and presented closer instrumental spreadability values to control samples. This indicates a strong market potential for optimised carob spreads.
\end{abstract}

\section{Introduction}

A growing body of literature that recognises the relationship between diet and health increased consumer demand for foods with sensorial quality and health-promoting nutritional components. Carob (Ceratonia siliqua L.) is a valuable plant source of sugar (more than 50\%, mainly sucrose), dietary fibre, polyphenols (mainly tannins), and minerals such as calcium, phosphorous, and potassium $[1,2]$. The chemical composition of carob fruit differs widely according to carob varieties and climate. Turkey is one of the main producer countries of carob worldwide with an average annual production and shares $5 \%$ of the world total export and production [2]. Generally, carob fruits have been used in industries such as pharmaceutical, food, textile, and cosmetics ones [3].
Carob flour is important for a wide range of industrial processes of food products such as candies, ice cream, drinks, and cakes, and it is produced by kibbling, roasting, and milling of carob pods. It is known as a natural sweetener with appearance and flavour similar to cocoa; thus, it is widely used as a cocoa substitute [4]. According to previous studies, the cocoa-like aroma could be generated due to thermal degradation of sugar content and the formation of some odorants via Maillard reaction [5]. In addition, the advantage of carob flour as a cocoa substitute is that it is naturally free from caffeine and theobromine whereas cocoa has relatively high amounts of these antinutrient components and has fewer calories [6]. In view of carob flours high nutritional value, there is a growing area of research by exploring it as a functional ingredient. Thus far, numerous studies have examined the enhancement of nutritional value with carob flour such as 
pastas, breads, tarhana, biscuits, and cakes $[3,7,8]$. However, most carob pods are discarded and not effectively utilized in Turkey.

Spreads have been widely accepted worldwide and based on sugar, fat, milk powder, lecithin, and so forth. The texture properties of spreads, such as hardness and hardness work done values (as related to spreadability), are commonly used to predict consumer acceptance and for spread quality evaluation. Several studies have systematically examined the use of instrumental texture analysis to assess the quality of spreads such as sunflower butter preparation, peanut butter, and chocolate spreads optimisation, as well as on investigation of other types of spreads [9].

Moreover, both particle size and composition are crucial for obtaining desirable spreadability values. Generally, smaller particle sizes and higher fat contents are known to improve the sensorial quality of spreads [10]. Nevertheless, there is much less information about the utilization of carob flour in spread production.

The objective of this study was to formulate an acceptable functional spread using carob flour and to investigate the textural, sensorial, colour, and nutritional properties of the spreads.

\section{Materials and Methods}

2.1. Materials. Hydrogenated palm oil, commercial skim milk powder, soy flour, lecithin, and hazelnut puree were provided by Anı Biscuit and Food Industry Inc. (Karaman, Turkey). Five commercial chocolate spreads (control samples) were purchased from a local market in Mersin. Carob flour (CF) was procured from GKM Food Additives Ltd. (Mersin, Turkey). Prior to analysis, all CF samples were milled with a laboratory mill (IKA, M20, Labortechnik, Staufen, Germany) and three fractions of this flour (125$100 \mu \mathrm{m}, 100-63 \mu \mathrm{m}$, and $63-32 \mu \mathrm{m}$ ) were separated using sieves of $125,100,63$, and $32 \mu \mathrm{m}$. All the ingredients and chocolate spreads were stored at $4^{\circ} \mathrm{C}$, until analyses.

2.2. Chemicals. Gallic acid (G7384), Folin-Ciocalteu's phenol reagent (F9252), $\mathrm{Na}_{2} \mathrm{CO}_{3}$ (S7795), potassium ferrocyanide (Carrez I) and zinc acetate (Carrez II), acetonitrile (HPLC grade), and HMF standard (HPLC grade) were obtained from Sigma (Sigma-Aldrich, St. Louis, Mo, USA). $\mathrm{HNO}_{3}$, hexane, $\mathrm{HCl}$, and $\mathrm{HClO}_{4}$ were of analytical grade (Merck, Darmstadt, Germany).

\subsection{Sample Preparation}

2.3.1. Spread Preparation. Spread samples with different formulations were prepared according to the method reported by Emadzadeh et al. [11]. All ingredients were homogenized using Ultra-Turrax (T50, IKA Labortechnik, Staufen, Germany) at $9500 \mathrm{rpm}$ for $10 \mathrm{~min}$ and the basic formulations were established by the preexperiments. As shown in Table 1, different amounts of carob flour (CF) and hydrogenated palm oil (HPO) were blended with a constant content $(80 \%$, $\mathrm{w} / \mathrm{w}$ ). The amount of all other ingredients (milk powder,
TABLE 1: Percentage of ingredients in formulations.

\begin{tabular}{lcccccc}
\hline $\begin{array}{l}\text { Sample } \\
\text { number }\end{array}$ & $\begin{array}{c}\text { Carob } \\
(\%)\end{array}$ & $\begin{array}{c}\text { HPO }^{*} \\
(\%)\end{array}$ & $\begin{array}{c}\text { Milk } \\
\text { powder } \\
(\%)\end{array}$ & $\begin{array}{c}\text { Soybean } \\
\text { flour } \\
(\%)\end{array}$ & $\begin{array}{c}\text { Lecithin } \\
(\%)\end{array}$ & $\begin{array}{c}\text { Hazelnut } \\
\text { puree } \\
(\%)\end{array}$ \\
\hline CF42 & 42 & 38 & 10 & 5 & 1 & 4 \\
CF40 & 40 & 40 & 10 & 5 & 1 & 4 \\
CF38 & 38 & 42 & 10 & 5 & 1 & 4 \\
CF36 & 36 & 44 & 10 & 5 & 1 & 4 \\
CF34 & 34 & 46 & 10 & 5 & 1 & 4 \\
CF32 & 32 & 48 & 10 & 5 & 1 & 4 \\
\hline
\end{tabular}

${ }^{*}$ Hydrogenated palm oil.

$10 \%$; soybean flour, 5\%; lecithin, $1 \%$; hazelnut puree, $4 \%$ ) was kept in constant ratio (20\%). Therefore, the variations could be clearly attributed to the influence of HPO and CF. Chocolate spread was used as the target product due to its great popularity worldwide. Therefore, five commonly consumed commercial chocolate spreads were selected as control samples. The optimised spread that presented closer instrumental spreadability values to control samples and has higher sensory score was selected for chemical analysis. The spreads were stored at ambient temperature $\left(26 \pm 2^{\circ} \mathrm{C}\right)$, and all measurements were performed within one week.

2.3.2. Sample Defatting. Spread samples $(8 \mathrm{~g})$ were washed with $3 \times 45 \mathrm{~mL}$ of hexane in order to remove lipid components as previously described by Adamson et al. [12] and the residue was then air dried.

\subsection{Measurement of Quality Characteristics}

2.4.1. Texture (Spreadability). Instrumental texture profile analysis (TPA) of spreads was performed using Texture Analyzer (Model TA-XT2; Stable Micro Systems, Surrey, UK) with respect to spreadability parameters including hardness and hardness work done values [13]. Data were extracted from the force-time curve with Texture Expert Exceed 2.3. software (Stable Micro System, Survey, UK). Spreadability was measured with a conical spreadability rig (Model HDP/SR, Stable Micro Systems, Ltd.) at room temperature $\left(25 \pm 2^{\circ} \mathrm{C}\right)$. Samples were filled into female cones to avoid air pockets and levelled to obtain a uniform surface. Each sample was penetrated with a corresponding male cone to a distance $2 \mathrm{~mm}$ from the bottom of the sample holder. The instrument was operated at test speed $=3 \mathrm{~mm} / \mathrm{s}$, posttest speed $=10 \mathrm{~mm} / \mathrm{s}$, and distance $=$ $30 \mathrm{~mm}$ with automatic detection of the force with a $5 \mathrm{~kg}$ load cell (trigger force $=5 \mathrm{~g}$ force) .

2.4.2. Colour. Colour measurements were carried out with the Colour Quest XE colorimeter (Hunter Lab., Hunter Assoc. Laboratory, Reston, VA, USA) using the illuminant D65 and observation angle of $10^{\circ}$ in reflectance specular excluded (RSEX) mode. The results were expressed in CIELAB system as $L^{*}, a^{*}$, and $b^{*}$ parameters indicating lightness (+ve) to darkness ( $-\mathrm{ve})$, redness (+ve) to greenness $(-\mathrm{ve})$, and yellowness $(+\mathrm{ve})$ to blueness $(-\mathrm{ve})$, respectively. 
The instrument was standardized prior to measurement with a standard light trap, followed by white and green calibration plates $(X=18.99 ; Y=24.27 ; Z=20.22)$. All results presented are the average of at least three measurements from different quadrants of each sample.

2.4.3. Overall Acceptability. Overall acceptability of spread samples was assessed using a nine-point hedonic scale (1: extremely dislike to 9: extremely like) with a trained panel of 12 judges [14]. The panellists were selected from staff members and graduate students (50\% males, $50 \%$ females, $20-45$ years, mean age 26, and nonsmokers) of Mersin University (Food Engineering Department) and who were experienced in the sensory evaluation of foods. Approximately $15 \mathrm{~g}$ of spreads was portioned in clear plastic cups coded with three random digits, and the samples were presented at room temperature under normal lighting conditions. Bread pieces and knives were provided to the assessors as carriers, and the social interaction was not allowed. The panellists were required to cleanse their palates with water between samples, and three spreads were evaluated in each session $24 \mathrm{~h}$ after production.

2.5. Total Phenolic Content (TPC). Total phenolic content (TPC) of spreads was estimated by the Folin-Ciocalteu spectrophotometric method by adapting the procedure used by Singleton and Rossi [15] with slight modifications. Briefly, the defatted sample $(1 \mathrm{~g})$ was extracted with $25 \mathrm{~mL}$ of distilled water and filtered through Whatman No. 1 paper. The extract $(0.2 \mathrm{~mL})$ was added to $1.5 \mathrm{~mL}$ of 10 -fold freshly diluted Folin-Ciocalteu reagent and allowed to react for $5 \mathrm{~min}$. Then, $1.5 \mathrm{~mL}$ of saturated sodium carbonate $(7.5 \%$, $\mathrm{Na}_{2} \mathrm{CO}_{3}$ ) aqueous solution was added and incubated at room temperature for $90 \mathrm{~min}$. The absorbance of the resulting bluecoloured mixture was recorded at $765 \mathrm{~nm}$ using a UV/VIS spectrophotometer (Lambda EZ201, Perkin Elmer, USA). Measurements were conducted in triplicate, and the results were expressed as milligrams of equivalent gallic acid per $100 \mathrm{~g}$ of spread sample.

2.6. HMF. HMF analysis was carried out following the chromatographic method described by Garcia-Villanova et al. [16]. Briefly, the defatted sample $(0.4 \mathrm{~g})$ was suspended in water $(7 \mathrm{~mL})$ and placed in a $10 \mathrm{~mL}$ centrifuge tube. After vigorously shaking for $1 \mathrm{~min}$, the blend was centrifuged at $5000 \mathrm{rpm}$ for $10 \mathrm{~min}$ and $0.5 \mathrm{~mL}$ each of Carrez I and Carrez II reagents was added with stirring. The supernatant centrifuged again under same conditions and the volume was adjusted to $25 \mathrm{~mL}$ with deionised water. The extract was filtered through a $0.45 \mu \mathrm{m}$ membrane and the filtrate was injected into HPLC. Quantitation was conducted with Agilent 1200 HPLC system (Agilent Technologies, CA, USA) consisting of a quaternary pump (G1311A), an autosampler (G1367C), a UV detector (G1353B) set at $284 \mathrm{~nm}$, and a temperature-controlled column oven (Agilent Technologies, CA, USA). HMF separations were performed on an Agilent Zorbax SB-C18 column $(5 \mu \mathrm{m}, 250 \mathrm{~mm} \times 4.6 \mathrm{~mm})$ with a flow rate of $1 \mathrm{~mL} / \mathrm{min}, 20 \mu \mathrm{L}$ injection volume, and the mobile
TABLE 2: Work specification resume for ICP-MS.

\begin{tabular}{lc}
\hline Plasma conditions & \\
\hline RF power & $1500 \mathrm{w}$ \\
Plasma gas flow rate & $15 \mathrm{~L} / \mathrm{min}$ \\
Auxiliary gas flow rate & $1 \mathrm{~L} / \mathrm{min}$ \\
Carrier gas flow rate & $1.1 \mathrm{~L} / \mathrm{min}$ \\
Spray chamber & $2^{\circ} \mathrm{C}$ \\
Sample depth & $8.6 \mathrm{~mm}$ \\
Sample introduction flow rate & $1 \mathrm{~mL} / \mathrm{min}$ \\
Nebuliser pump & $0.1 \mathrm{rps}$ \\
Extract lens $(\mathrm{V}), 1.5$ & $1.5 \mathrm{~V}$ \\
Spray chamber & $2^{\circ} \mathrm{C}$ \\
\hline
\end{tabular}

TABLE 3: Effect of particle size on instrumental spreadability values.

\begin{tabular}{lcc}
\hline Particle size $(\mu \mathrm{m})$ & Hardness $(\mathrm{kg})$ & Hardness work done $(\mathrm{kg} \cdot \mathrm{s})$ \\
\hline $63-32 \mu \mathrm{m}$ & $7.89 \pm 0.13^{\mathrm{a}}$ & $8.76 \pm 0.11^{\mathrm{a}}$ \\
$100-63 \mu \mathrm{m}$ & $6.53 \pm 0.29^{\mathrm{b}}$ & $7.27 \pm 0.07^{\mathrm{b}}$ \\
$125-100 \mu \mathrm{m}$ & $5.71 \pm 0.20^{\mathrm{c}}$ & $6.78 \pm 0.07^{\mathrm{c}}$ \\
\hline
\end{tabular}

Means in same column with different superscripts are significantly different $(p<0.05)$.

phase of water: acetonitrile $(5: 95, \mathrm{v} / \mathrm{v})$. Stock solution was prepared and diluted to the appropriate concentrations for calibration.

2.7. Mineral Content. Mineral contents of carob spreads were evaluated using an inductively coupled plasma-mass spectrometer (ICP-MS) (Agilent 7500ce series ICP/MS; Agilent Technologies Inc.) equipped with octopole reaction system. A microwave oven (MARS 240/50; CEM, Matthews, NC, USA) was adopted for the decomposition of the samples with concentrated acid solutions. For this purpose, the samples were prepared for digestion according to the procedure used by Başgel and Erdemoğlu [17]. Following the digestion process, the samples were diluted with ultrapure deionised water. All the digests were analysed using ICP-MS and the operating conditions were shown in Table 2. For calibration, multielement calibration standard 2A (Agilent Technologies, Santa Clara, CA, USA) was used.

2.8. Statistical Analysis. All values were expressed as mean \pm SD (standard deviation) and all analyses were carried out in triplicate. Significant differences among the means were evaluated using ANOVA with LSD test $(p<0.05)$ and statistical analysis was performed by a commercial software package (STATISTICA 8.0, StatSoft Inc., Tulsa, OK, USA).

\section{Results and Discussion}

3.1. Effect of Particle Size Reduction on Spreadability. As can be seen from Table 3, reducing particle size of CF samples inclined a statistically significant adverse effect on instrumental spreadability values $(p<0.05)$. This trend is in line with those of previous studies and it has commonly been assumed that reducing particle size increases hardness 
TABLE 4: Instrumental spreadability, sensory, and colour values of the formulations.

\begin{tabular}{|c|c|c|c|c|c|c|c|c|}
\hline $\begin{array}{l}\text { Sample } \\
\text { number }\end{array}$ & $\begin{array}{c}\text { CF } \\
(\mathrm{g} / 100 \mathrm{~g} \mathrm{CS})\end{array}$ & $\begin{array}{c}\text { HPO } \\
(\mathrm{g} / 100 \mathrm{~g} \mathrm{CS})\end{array}$ & $\begin{array}{l}\text { Hardness } \\
\quad(\mathrm{kg})\end{array}$ & $\begin{array}{c}\text { Hardness } \\
\text { work done } \\
(\mathrm{kg} \cdot \mathrm{s})\end{array}$ & OAA & $L^{*}$ & $a^{*}$ & $b^{*}$ \\
\hline Control & & & $5.71 \pm 0.01^{\mathrm{c}}$ & $7.82 \pm 0.01^{\mathrm{g}}$ & $7.83 \pm 1.00^{*}$ & $37.88 \pm 0.15^{\mathrm{a}}$ & $5.26 \pm 0.17^{\mathrm{a}}$ & $7.26 \pm 0.05^{\mathrm{a}}$ \\
\hline CF42 & 42 & 38 & $16.67 \pm 0.13^{\mathrm{a}}$ & $18.68 \pm 0.25^{\mathrm{a}}$ & $3.23 \pm 1.01$ & $23.34 \pm 0.09^{b}$ & $8.56 \pm 0.07^{\mathrm{b}}$ & $8.13 \pm 0.09^{\mathrm{b}}$ \\
\hline CF40 & 40 & 40 & $10.74 \pm 0.10^{\mathrm{b}}$ & $12.26 \pm 0.07^{\mathrm{b}}$ & $4.85 \pm 0.65$ & $29.88 \pm 0.08^{c}$ & $8.05 \pm 0.04^{c}$ & $8.62 \pm 0.01^{c}$ \\
\hline CF38 & 38 & 42 & $5.78 \pm 0.07^{\mathrm{c}}$ & $6.71 \pm 0.20^{c}$ & $7.06 \pm 1.43^{*}$ & $34.36 \pm 0.09^{d}$ & $7.64 \pm 0.11^{\mathrm{d}}$ & $9.06 \pm 0.16^{\mathrm{d}}$ \\
\hline CF36 & 36 & 44 & $3.78 \pm 0.04^{\mathrm{d}}$ & $4.21 \pm 0.18^{\mathrm{d}}$ & $4.70 \pm 0.72$ & $35.65 \pm 0.04^{\mathrm{e}}$ & $7.2 \pm 0.12^{\mathrm{e}}$ & $9.53 \pm 0.05^{\mathrm{e}}$ \\
\hline CF34 & 34 & 46 & $2.17 \pm 0.03^{\mathrm{e}}$ & $3.16 \pm 0.03^{\mathrm{e}}$ & $2.41 \pm 1.10$ & $37.71 \pm 0.07^{\mathrm{f}}$ & $6.75 \pm 0.07^{\mathrm{f}}$ & $9.88 \pm 0.04^{f}$ \\
\hline CF32 & 32 & 48 & $1.22 \pm 0.09^{f}$ & $1.56 \pm 0.04^{\mathrm{f}}$ & $1.74 \pm 0.75$ & $41.84 \pm 0.11^{\mathrm{g}}$ & $6.43 \pm 0.04^{\mathrm{g}}$ & $10.47 \pm 0.09^{\mathrm{g}}$ \\
\hline
\end{tabular}

${ }^{*}$ No significant differences were found between control and CF 38 for OAA scores.

Means in same column with different superscripts are significantly different $(p<0.05)$.

CF: percentage of carob flour in carob spreads.

CS: carob spread.

HPO: percentage of hydrogenated palm oil in carob spreads.

OAA: overall acceptability scores.

due to increasing overall surface area [10]. In the texture analysis of reduced-fat peanut butter by Lima et al. [18], it was found that the instrumental hardness was very dependent on the particles size. In addition, decreasing particle size improves sensory properties [10], and therefore the smallest particle size range $(63-32 \mu \mathrm{m})$ was selected for carob spread preparation. Although particle size reduction, the carob flour samples had greater particle size than cocoa powders (18$30 \mu \mathrm{m})$. A possible explanation for the failure to reach the smaller particle size values might be attributed to the high sugar and moisture levels of carob compared to cocoa [4].

3.2. Textural Properties. Spreadability is a key textural attribute affecting consumer acceptance in confectionery or gelled products like spreads, cheeses, and jams. Spreadability has been defined as the ease to apply a spread on a piece of bread or cracker and is expressed in terms of hardness and hardness work done. Hardness (firmness) shows the maximum force required for a probe to penetrate the sample and the spreadability decreases with increasing the hardness value. Hardness work done $(\mathrm{kg} \mathrm{s})$ is defined as the total amount of force required to carry out the shearing process and is a measure of ease of spreadability [13]. A typical forcetime curve of CS samples, gained from texture profile analysis (TPA), was set out in Figure 1.

As shown in Table 4, hardness and hardness work done values decreased with the increasing of HPO content. The observed rise in spreadability could be attributed to fat content. HPO was added to the formulations in order to reduce the hardening effect of $\mathrm{CF}$ and increase spreadability. Factors thought to be influencing instrumental texture values have been explored and focused on fat content in several studies. Afoakwa et al. [19] argue that coating of fat on particle surfaces reduces interparticle interaction and induces flow in a direct relationship with fat content in dark chocolate. Similarly, Beckett [10] in his book notes that the majority of the fat plays a key role in wetting the solid media, which is partially connected to the particle surfaces. Nattress et al. [20] demonstrated that the hardness values of dark chocolate

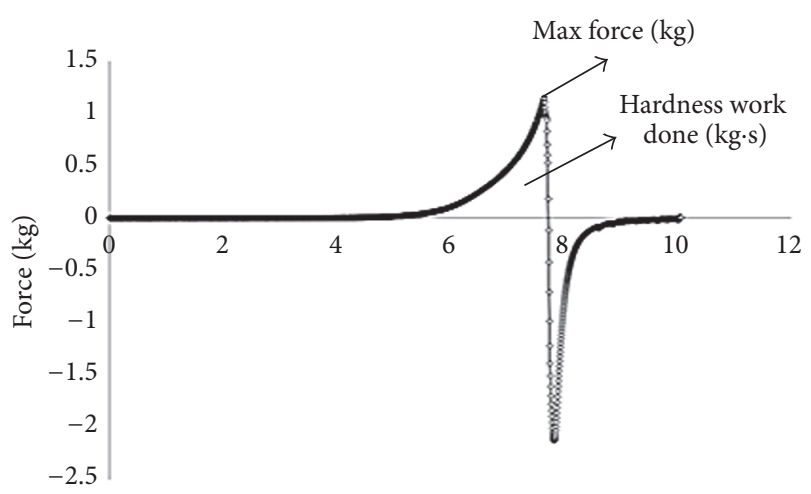

FIGURE 1: Typical texture profile analysis curve of carob spreads.

spreads significantly decreased with increasing hazelnut oil content due to changes in solid fat content. In the same vein, adverse effect of solid fat content on hardness values was found in chocolate spreads by Full et al. [21]. However, Radočaj et al. [9] reported that the lowering of hemp oil content may reduce the hardness values in spread samples.

3.3. Colour. The colour of a food plays a vital role in product commercialization and is directly affected by the ingredients making up the formulation. Table 4 provides the results obtained from the instrumental colour analysis of spread samples. There was a gradual decrease in lightness $\left(L^{*}\right)$ values with increasing $\mathrm{CF}$ and the samples were characterized by a darker colour. This result was expected since the dark coloured carob flour was the major component of carob spread formulations and directly influenced the product colour. In addition, carob flour slightly influenced the redness parameters; therefore, all samples presented little reddish colouration. It might be as a result of Maillard reaction and caramelisation during the roasting process of carob flour [22]. On the other hand, HPO enhanced yellowness and the samples containing higher amounts of HPO were characterized by higher values for parameter $b^{*}$. 
TABLE 5: Concentrations of several minerals in carob spreads and percentages of recommended dietary allowances or adequate intakes.

\begin{tabular}{|c|c|c|c|c|c|c|c|}
\hline \multirow[b]{2}{*}{ Minerals } & \multicolumn{2}{|c|}{ RDA or AI (mg/day) } & \multirow[b]{2}{*}{ Children $^{\mathrm{a}}$} & \multirow{2}{*}{$\begin{array}{l}\text { Carob spread } \\
(\mathrm{mg} / 100 \mathrm{~g})\end{array}$} & \multicolumn{3}{|c|}{ RDA or AI (\%) } \\
\hline & Adult males ${ }^{\mathrm{a}}$ & Adult females ${ }^{\mathrm{a}}$ & & & Adult males ${ }^{\mathrm{a}}$ & Adult females ${ }^{\mathrm{a}}$ & Children $^{\mathrm{a}}$ \\
\hline $\mathrm{Ca}^{*}$ & 1000 & 1000 & 1000 & $350.41 \pm 9.90$ & 14.89 & 14.89 & 14.89 \\
\hline $\mathrm{Mg}$ & $400-420$ & $310-320$ & 130 & $63.52 \pm 2.20$ & $6.43-6.75$ & $8.44-8.71$ & 20.77 \\
\hline $\mathrm{Fe}$ & 8 & 18 & 10 & $4.13 \pm 0.08$ & 21.92 & 9.74 & 17.53 \\
\hline $\mathrm{P}$ & 700 & 700 & 500 & $435.64 \pm 8.90$ & 26.45 & 26.45 & 37.03 \\
\hline K & 4700 & 4700 & 3800 & $1271.29 \pm 6.50$ & 11.50 & 11.50 & 14.22 \\
\hline $\mathrm{Zn}$ & 11 & 8 & 5 & $0.57 \pm 0.02$ & 2.20 & 3.02 & 4.84 \\
\hline $\mathrm{Na}$ & 1500 & 1500 & 1200 & $120.33 \pm 1.14$ & 3.41 & 3.41 & 4.26 \\
\hline
\end{tabular}

Values were based on $\sim 42.5 \mathrm{~g}$ (1.5 ounces) carob spread serving.

RDA: recommended dietary allowances; AI: adequate intake.

*Values are expressed as AI.

${ }^{\mathrm{a}}$ Recommended dietary allowances (RDA) or adequate intake (AI) for adults (aged 19-50 years) and children (aged 4-8 years).

Consequently, these samples were more intensely brown. In accordance with the present results, Çağlar et al. [8] have demonstrated that the carob flour has dark and reddish colour and decreases lightness, greenness, and yellowness values. Additionally, increasing carob flour concentration in formulations presented an adverse effect on the panellists in sensory analysis due to the reduction of lightness.

3.4. Overall Acceptability. Results from earlier studies demonstrate a strong and consistent association between consumer acceptability and product commercialization [23]. A comparison of the overall acceptability scores for the evaluated spread samples is presented in Table 4. The higher amounts of CF and HPO were not accepted and there was a gradual rise in OAA scores with the increasing of HPO content. It can therefore be assumed that the enhancement of HPO improves the acceptability of the samples. These results are consistent with those of Swanson and Perry [24] who suggested that the reduction of fat in modified oatmeal and chocolate chip cookies influenced the acceptability adversely. CF38 tended to receive the highest OAA scores compared to other spreads and presented closer instrumental spreadability values to control samples. Thus, it can be considered as sensorially acceptable and the potential product for market purposes.

3.5. Mineral Content. Mineral contents of spread samples were presented in Table 5; several minerals were identified and quantified: potassium $(\mathrm{K})$, iron $(\mathrm{Fe})$, calcium $(\mathrm{Ca})$, magnesium $(\mathrm{Mg})$, phosphorus $(\mathrm{P})$, zinc $(\mathrm{Zn})$, and sodium $(\mathrm{Na})$. It is apparent from the table that potassium is the predominant mineral followed by phosphorus, calcium, and sodium in carob spreads and it can be suggested that the formulated spreads served as an excellent source of phosphorus, magnesium, iron, and calcium [25]. These results are in accordance with the data of Özcan et al. [26] indicating slight differences which may be due to the effect of several factors (climate, variety, geographical origin, etc.) on mineral content. The main functions of essential minerals consist of rigid bone formation, transmission of nerve impulses, metabolic reactions, maintenance of colloidal system, and regulation of acid-base equilibrium [27]. Minerals are also known as crucial components of hormones, enzymes, and enzyme activator [28]. According to results, it can therefore be assumed that the carob spread is a promising source for essential minerals in human metabolism that are responsible for healthier growth and prevention of diseases.

3.6. Total Phenolic Content (TPC). Polyphenolic compounds have been regarded as significant bioactive compounds due to their ability to protect against diseases like cancer, coronary heart disease, neurodegenerative disorders, and so forth [29]. The total phenolic content of formulated spread was approximately $615.28 \pm 26.2 \mathrm{mg} \mathrm{GAE} / 100 \mathrm{~g}$ and the result is in line with those of previous studies [30,31]. Makris and Kefalas [32] reported that carob pod is more effective source of antioxidants than red wines. It can thus be suggested that the carob spreads might be useful as a potential nutraceutical resource considering its high phenolic content. On the other hand, due to antioxidant potential of carob flour, it could delay lipid peroxidation and thus it could enhance the product shelf life. According to previous studies, carob flour was generally shown to have high content of tannins [32]. The consumption of tannins has been associated with bitter, acrid, and astringent taste; therefore, they generally affect the consumer acceptance adversely [33]. However, as shown in Table 4, the addition of $38 \%$ carob flour was found to have no negative effect on OAA scores.

3.7. HMF. HMF has been widely used as an indicator of quality loss and may form as a result of excessive heating and/or preservation processes. It has been noted that HMF has a variety of harmful effects including mutagenic, carcinogenic, and cytotoxic [34]. Carob flour is generally submitted to thermal processing, mainly roasting, to obtain characteristic sensory features. There has been no international standard for carob flour and hence it might be compared with the standards of honey that can be considered as a similar product since it contains high sugar and mineral contents. According to Codex Standard, HMF concentration of processed honey should be under $40 \mathrm{ppm}$ [35]. HMF values of the carob spread were about $3.96 \pm 0.06 \mathrm{ppm}$ that was lower than the standard 
of honey. The result corroborates with the earlier study of Vitali Čepo et al. [6] which showed that the measurable quantities of HMF are found in carob flour samples. On the other hand, carob pods have been widely consumed as carob molasses in Turkey and they have been reported to have higher HMF content (namely, 21.32 ppm) [36]. According to these values, the high level of HMF found in carob molasses could set a limit to its daily consumption. The present study demonstrates the significant advantage of consuming carob spread comparing to carob molasses.

\section{Conclusion}

The purpose of the current study was to formulate acceptable carob spreads and to determine their textural, colour, sensory, and some nutritional properties. Effects on product appearance, texture, and sensory scores depend on the level of carob flour and hydrogenated palm oil employed. The results of this investigation show that the spread containing $38 \mathrm{~g}$ carob flour and $42 \mathrm{~g}$ hydrogenated palm oil (for $100 \mathrm{~g}$ carob spread) was more acceptable and has closer spreadability values to chocolate spread. Overall, this study strengthens the idea that consumers will accept the carob spreads containing high nutritional value and allows product diversification in market. In addition, the present study paved the way for a better utilization of carob flour as an ingredient for functional food formulations. Further research could also be conducted to determine the storage stability of the formulated carob spreads.

\section{Competing Interests}

The authors declare that there is no conflict of interests regarding the publication of this paper.

\section{Acknowledgments}

This research was supported by Mersin University Scientific Research Project (Project no. BAP-FBE GM (SA) 2010-2 YL). The authors are also grateful to Anı Biscuit and Food Industry Inc. (Karaman, Turkey) for supplying hydrogenated palm oil, commercial skim milk powder, soy flour, lecithin, and hazelnut puree.

\section{References}

[1] M. M. Özcan, D. Arslan, and H. Gökçalik, "Some compositional properties and mineral contents of carob (Ceratonia siliqua) fruit, flour and syrup," International Journal of Food Sciences and Nutrition, vol. 58, no. 8, pp. 652-658, 2007.

[2] B. Biner, H. Gubbuk, M. Karhan, M. Aksu, and M. Pekmezci, "Sugar profiles of the pods of cultivated and wild types of carob bean (Ceratonia siliqua L.) in Turkey," Food Chemistry, vol. 100, no. 4, pp. 1453-1455, 2007.

[3] Ł. Sęczyk, M. Świeca, and U. Gawlik-Dziki, "Effect of carob (Ceratonia siliqua L.) flour on the antioxidant potential, nutritional quality, and sensory characteristics of fortified durum wheat pasta," Food Chemistry, vol. 194, pp. 637-642, 2016.
[4] A. K. Yousif and H. M. Alghzawi, "Processing and characterization of carob powder," Food Chemistry, vol. 69, no. 3, pp. 283287, 2000.

[5] H. H. M. Fadel, M. A. Abdel Mageed, A. K. M. E. Abdel Samad, and S. N. Lotfy, "Cocoa substitute: evaluation of sensory qualities and flavour stability," European Food Research and Technology, vol. 223, no. 1, pp. 125-131, 2006.

[6] D. Vitali Čepo, A. Mornar, B. Nigović, D. Kremer, D. Radanović, and I. Vedrina Dragojević, "Optimization of roasting conditions as an useful approach for increasing antioxidant activity of carob powder," LWT-Food Science and Technology, vol. 58, no. 2, pp. 578-586, 2014.

[7] N. Ortega, A. Macià, M.-P. Romero, J. Reguant, and M.-J. Motilva, "Matrix composition effect on the digestibility of carob flour phenols by an in-vitro digestion model," Food Chemistry, vol. 124, no. 1, pp. 65-71, 2011.

[8] A. Çağlar, N. Erol, and M. S. Elgün, "Effect of carob flour substitution on chemical and functional properties of tarhana," Journal of Food Processing and Preservation, vol. 37, no. 5, pp. 670-675, 2013.

[9] O. Radočaj, E. Dimić, L. L. Diosady, and V. Vujasinović, "Optimizing the texture attributes of a fat-based spread using instrumental measurements," Journal of Texture Studies, vol. 42, no. 5, pp. 394-403, 2011.

[10] S. Beckett, The Science of Chocolate, 2008.

[11] B. Emadzadeh, S. M. A. Razavi, and G. Schleining, "Dynamic rheological and textural characteristics of low-calorie pistachio butter," International Journal of Food Properties, vol. 16, no. 3, pp. 512-526, 2013.

[12] G. E. Adamson, S. A. Lazarus, A. E. Mitchell et al., "HPLC method for the quantification of procyanidins in cocoa and chocolate samples and correlation to total antioxidant capacity," Journal of Agricultural and Food Chemistry, vol. 47, no. 10, pp. 4184-4188, 1999.

[13] S. Basu and U. S. Shivhare, "Rheological, textural, microstructural and sensory properties of mango jam," Journal of Food Engineering, vol. 100, no. 2, pp. 357-365, 2010.

[14] H. Stone and J. L. Sidel, Sensory Evaluation Practices, 3rd edition, 2004.

[15] V. L. Singleton and J. A. Rossi, "Colorimetry of total phenolics with phosphomolybdic-phosphotungstic acid reagents," American Journal of Enology and Viticulture, vol. 16, no. 3, pp. 144-158, 1965.

[16] B. Garcia-Villanova, E. Guerra-Hernández, E. MartínezGómez, and J. Montilla, "Liquid chromatography for the determination of 5-(hydroxymethyl)-2-furaldehyde in breakfast cereals," Journal of Agricultural and Food Chemistry, vol. 41, no. 8, pp. 1254-1255, 1993.

[17] S. Başgel and S. B. Erdemoğlu, "Determination of mineral and trace elements in some medicinal herbs and their infusions consumed in Turkey," Science of the Total Environment, vol. 359, no. 1-3, pp. 82-89, 2006.

[18] I. M. Lima, H. S. Guraya, and E. T. Champagne, "Improved peanut flour for a reduced-fat peanut butter product," Journal of Food Science, vol. 65, no. 5, pp. 854-861, 2000.

[19] E. O. Afoakwa, A. Paterson, and M. Fowler, "Effects of particle size distribution and composition on rheological properties of dark chocolate," European Food Research and Technology, vol. 226, no. 6, pp. 1259-1268, 2008. 
[20] L. A. Nattress, G. R. Ziegler, R. Hollender, and D. G. Peterson, "Influence of hazelnut paste on the sensory properties and shelflife of dark chocolate," Journal of Sensory Studies, vol. 19, no. 2, pp. 133-148, 2004.

[21] N. A. Full, S. Y. Reddy, P. S. Dimick, and G. R. Ziegler, "Physical and sensory properties of milk chocolate formulated with anhydrous milk fat fractions," Journal of Food Science, vol. 61, no. 5, pp. 1068-1084, 1996.

[22] L. Iipumbu, "Compositional Analysis of Locally Cultivated Carob (Ceratonia Siliqua) Cultivars and Development of Nutritional Food Products for a Range of Market Sectors," 2008.

[23] D. Granato, J. C. B. Ribeiro, I. A. Castro, and M. L. Masson, "Sensory evaluation and physicochemical optimisation of soybased desserts using response surface methodology," Food Chemistry, vol. 121, no. 3, pp. 899-906, 2010.

[24] R. B. Swanson and J. M. Perry, "Modified oatmeal and chocolate chip cookies: evaluation of the partial replacement of sugar and/or fat to reduce calories," International Journal of Consumer Studies, vol. 31, no. 3, pp. 265-271, 2007.

[25] U.S. Department of Agriculture (USDA), Food and Nutrition Information Center, National Agricultural Library, Beltsville, Md, USA, 2008.

[26] M. M. Özcan, D. Arslan, and H. Gökçalik, "Some compositional properties and mineral contents of carob (Ceratonia siliqua) fruit, flour and syrup," International Journal of Food Sciences and Nutrition, vol. 58, no. 8, pp. 652-658, 2007.

[27] H. Gençcelep, Y. Uzun, Y. Tunçtürk, and K. Demirel, "Determination of mineral contents of wild-grown edible mushrooms," Food Chemistry, vol. 113, no. 4, pp. 1033-1036, 2009.

[28] C. Alasalvar, K. D. A. Taylor, E. Zubcov, F. Shahidi, and M. Alexis, "Differentiation of cultured and wild sea bass (Dicentrarchus labrax): total lipid content, fatty acid and trace mineral composition," Food Chemistry, vol. 79, no. 2, pp. 145-150, 2002.

[29] P. S. Negi, G. K. Jayaprakasha, and B. S. Jena, "Antioxidant and antimutagenic activities of pomegranate peel extracts," Food Chemistry, vol. 80, no. 3, pp. 393-397, 2003.

[30] F. A. Ayaz, H. Torun, S. Ayaz et al., "Determination of chemical composition of anatolian carob pod (Ceratonia siliqua L.): sugars, amino and organic acids, minerals and phenolic compounds," Journal of Food Quality, vol. 30, no. 6, pp. 10401055, 2007.

[31] I. Turhan, N. Tetik, M. Aksu, M. Karhan, and M. Certel, "Liquid Solid Extraction of Soluble Solids," Liquid Solid Extraction of Soluble Solids, vol. 29, pp. 498-507, 2006.

[32] D. P. Makris and P. Kefalas, "Carob pods (Ceratonia siliqua L.) As a source of polyphenolic antioxidants," Food Technology and Biotechnology, vol. 42, no. 2, pp. 105-108, 2004.

[33] A. Drewnowski and C. Gomez-Carneros, "Bitter taste, phytonutrients, and the consumer: a review," American Journal of Clinical Nutrition, vol. 72, no. 6, pp. 1424-1435, 2000.

[34] E. Capuano and V. Fogliano, "Acrylamide and 5hydroxymethylfurfural (HMF): a review on metabolism, toxicity, occurrence in food and mitigation strategies," LWTFood Science and Technology, vol. 44, no. 4, pp. 793-810, 2011.

[35] C. Alimentarius, "Revised codex standard for honey," Codex Stan, vol. 12, p. 1982, 2001.

[36] M. Sengül, M. F. Ertugay, M. Sengül, and Y. Yüksel, "Rheological characteristics of carob pekmez," International Journal of Food Properties, vol. 10, no. 1, pp. 39-46, 2007. 

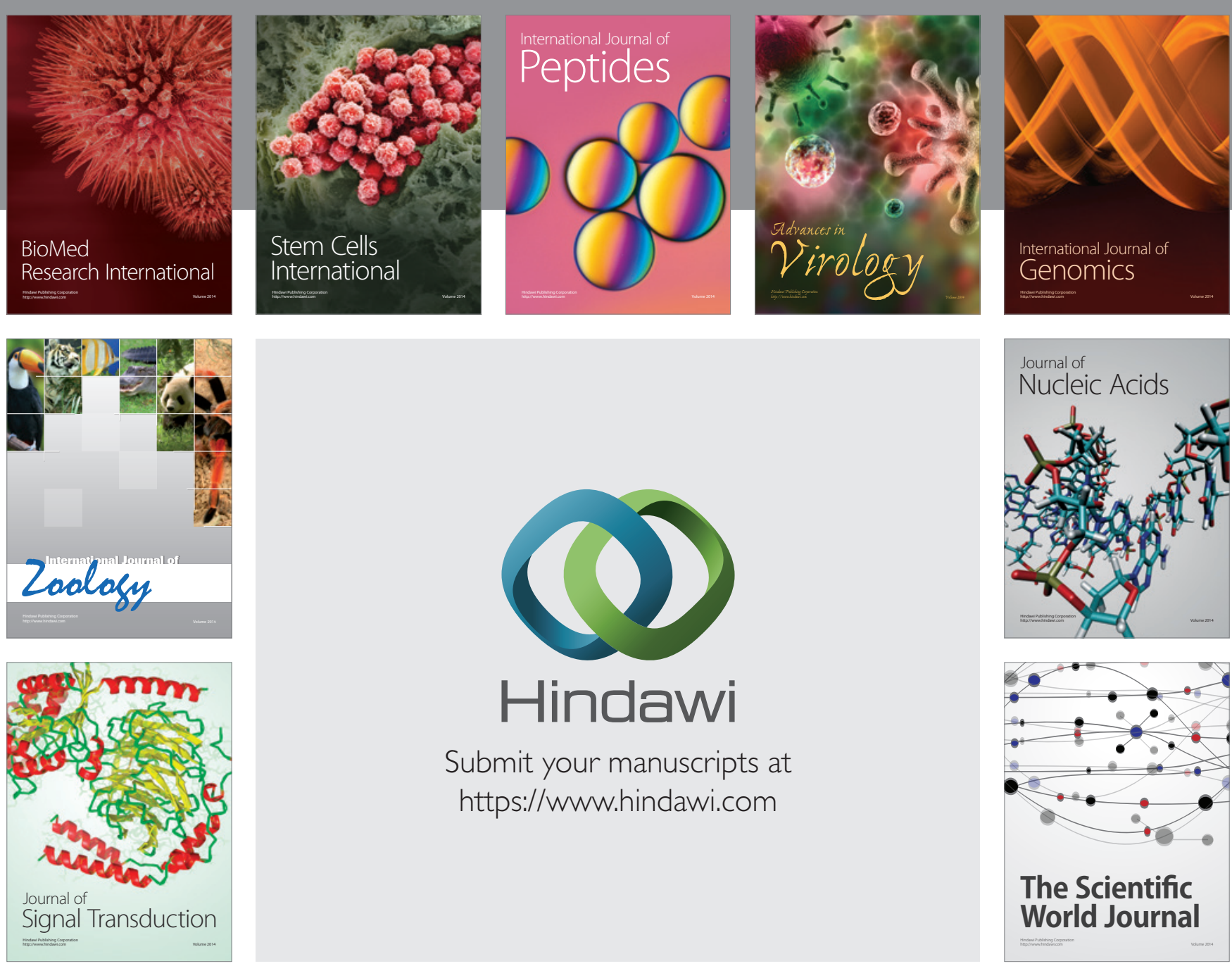

Submit your manuscripts at

https://www.hindawi.com
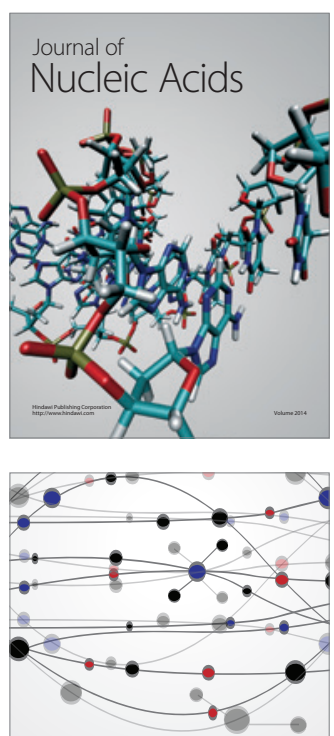

The Scientific World Journal
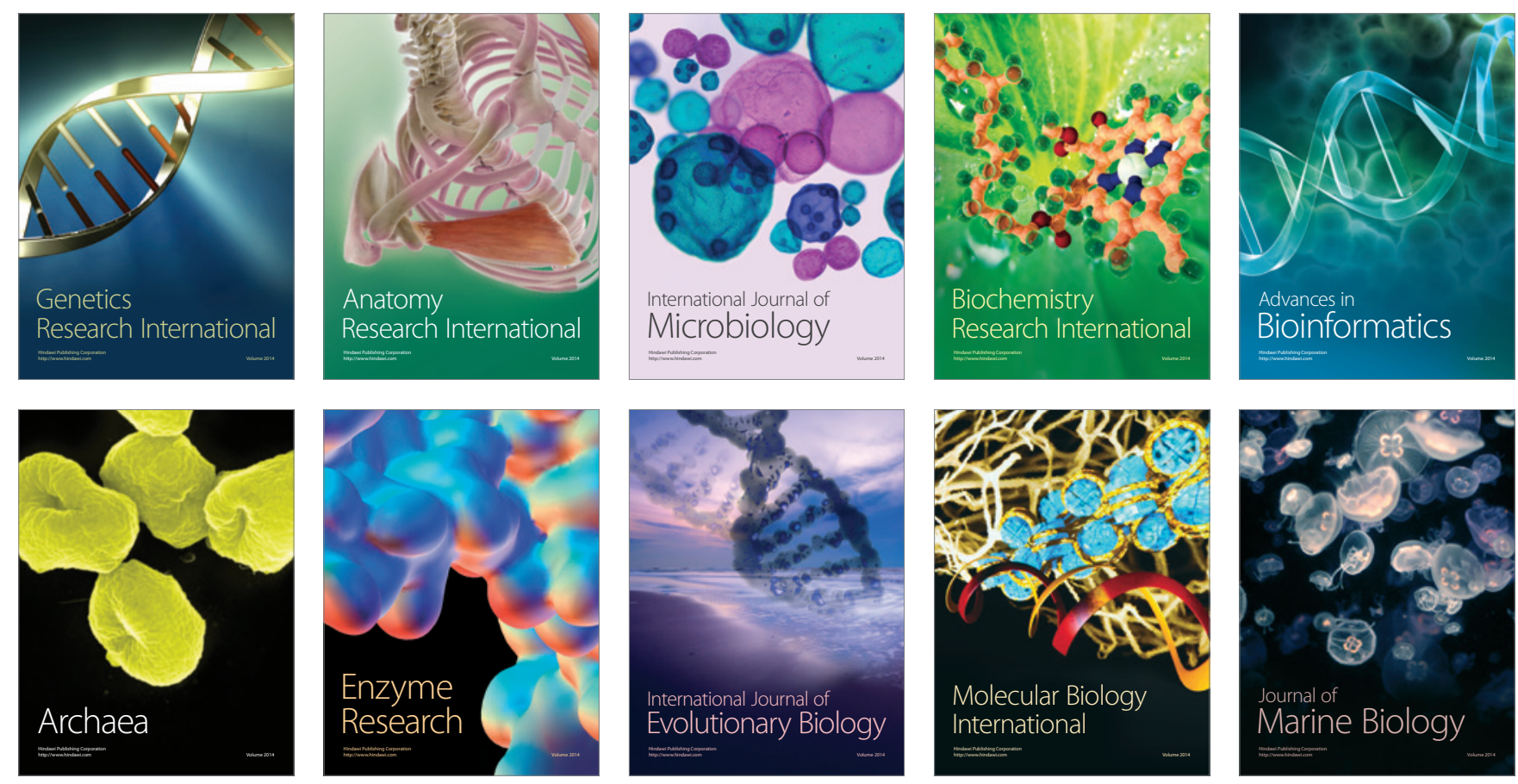